\title{
Obstructive Sleep Apnea: A Risk Factor for Type-2 Diabetes Mellitus
}

\author{
Majid Yaseen ${ }^{1}$, Masood Tanvir ${ }^{2}$, Ozaifa Kareem ${ }^{1}$, Suhail Ahmad Mir ${ }^{1}$, Rumaisa Rashid ${ }^{1}$, Syed Umer ${ }^{1}$ and G. N. \\ Bader $^{2 *}$ \\ ${ }^{1}$ Department of Pharmaceutical Sciences, University of Kashmir, Srinagar, India
}

${ }^{2}$ Department of General Medicine, Government Medical College, Srinagar, India

Submission: May 28, 2019; Published: July 17, 2019

*Corresponding author: Ghulam Nabi Bader, Department of Pharmaceutical Sciences, University of Kashmir, Hazratbal Srinagar, J\&K-190006, India

\begin{abstract}
Obstructive sleep apnea (OSA) is a chronic sleep-breathing disorder and a frequent comorbidity in patients with type-2 diabetes mellitus (T2DM). Cardinal features of OSA including arousals from sleep and fragmented sleep pattern have been implicated to cause oxygen desaturations and enhance the nocturnal release of cortisol that sustain during daytime thus providing the stimulus for the development of T2DM. OSA can promote new onset T2DM because intermittent hypoxia decrease insulin sensitivity and sympathetic hyperactivity leads to the release of inflammatory markers that induce insulin resistance. OSA is a common disorder affecting both men and women and it is estimated that $80-90 \%$ of people with OSA remain undiagnosed. An ever-growing number of studies support a robust association between OSA and T2DM including glucose intolerance and insulin resistance. Evidences from human and animal models provide an insight into the potential mechanisms that lead to altered glucose metabolism and poor glycemic control in OSA. This review summarizes the overlapping pathophysiology of OSA and T2DM and an overview of various treatment approaches to OSA
\end{abstract}

Keywords: OSA; T2DM; Glucose metabolism; Insulin resistance; Management; Intra-thoracic pressure; Sympathetic activity; Hypoxia; Hypercapnia; Hypertension; Stroke; Depression; Diabetes; High blood sugar; Glucose intolerance

Abbreviation: OSA: Obstructive Sleep Apnea; HPA: Hypothalamic-Pituitary-Adrenal; SDB: Sleep Disordered Breathing; PAP: Positive Airway Pressure; CPAP: Continuous Positive Airway Pressure; MMA: Maxillo-Mandibular Advancement; AASM: American Academy of Sleep Medicine; UPPP: Uvulopalatopharyngoplasty

\section{Introduction}

Obstructive sleep apnea (OSA) is a complex sleep disorder characterized by repetitive collapse of upper airway leading to cessation of airflow and greater respiratory effort [1]. The intermittent hypoxia, alternating with periods of normoxia, lead to transient arousals from sleep, restoring the airflow, but causing fragmentation of sleep and marked swings in intrathoracic pressure [2]. Also, sleep fragmentation associated with hypoxia and hypercapnia increases the sympathetic activity which in turn increases the blood sugar level by decreasing insulin sensitivity [3].

OSA is a common disease which is an independent risk factor for a number of conditions such as hypertension, [4] stroke, [5] depression [6] and diabetes [7]. It affects up to $20 \%$ of the population worldwide with approximately $5 \%$ experiencing excessive daytime sleepiness [8]. Its prevalence in India is estimated to be $7.5 \%$ [9]. On the other hand, T2DM is a growing challenge and an estimated worldwide prevalence of $6.4 \%$ occur among adults (aged 20-79 years) [10]. In India an estimated $8.7 \%$ of population suffer from T2DM [11]. It is characterized by presence of hyperglycemia either due to defective insulin secretion or defective insulin action or both [12]. The absence or reduced insulin secretion in turn leads to persistent high blood sugar and glucose intolerance [13]. Given the high prevalence, similar predisposition and overlapping pathophysiology of OSA and T2DM, they can be expected to occur concurrently in the same patient.

\section{Pathophysiological Link between OSA and Type 2 Diabetes Mellitus}

Sleep affects almost every type of tissue in the body from vital organs like brain, heart and lungs to metabolism, immune function, mood, and disease resistance. A chronic lack of sleep or poor quality of sleep is linked to the increased risk of disorders 
like high blood pressure, cardiovascular diseases, diabetes, depression and obesity [14]. Under normal conditions glucose homeostasis results from a controlled balance between glucose production and glucose utilization. The association between sleep duration and development of diabetes has been examined in many epidemiological studies. In a prospective study from Germany which followed 8269 non-diabetic men and women for a period of 7.5 years in average observed a significant increased risk of T2DM for those who reported difficulty in maintaining sleep at baseline [15].

Intermittent hypoxemia and sleep fragmentation are cardinal features of OSA and are likely in the causal pathway leading to metabolic dysfunction [16]. Short-term laboratory-based experiments in healthy human subjects have demonstrated that sleep restriction, sleep fragmentation and intermittent hypoxemia can lead to glucose metabolism dysregulation [17]. In healthy volunteers, exposure to 5 hours of intermittent hypoxia during wakefulness inducing an average of 24 desaturation events per hour, led to a $17 \%$ reduction in insulin sensitivity without a simultaneous increase in insulin secretion [18]. In another experiment, however, exposure to three hours of intermittent hypoxia (leading to 25 desaturations/hour) resulted in an increase in plasma glucose without changes in insulin secretion [19].

Therefore, there may be a threshold with regard to the intensity of hypoxemia or duration of exposure that may lead to an adverse impact on insulin sensitivity [20]. The role of sleep fragmentation on glucose metabolism has been demonstrated in multiple human experiments. Although the exact pathophysiologic and causal links between OSA and glucose metabolism dysregulation are not fully understood, multiple mechanistic pathways are likely to be causally involved. Direct recordings of muscle sympathetic nerve have demonstrated increased sympathetic activity in patients with OSA [21]. This sympatho-excitation persists during the daytime in untreated patients with OSA and is significantly reduced by effective CPAP therapy [22]. Most endocrine organ releasing hormones involved in glucose regulation are inhibited by elevations of sympathetic tone. Well-documented examples relevant to metabolic risk are pancreatic insulin secretion, hepatic glucose production, and adipocyte regulation of energy balance [23]. In addition, peptidergic factors originating from the intestine (glucagon-like peptide- 1 and glucose-dependent insulinotropic polypeptide) augment the insulin response induced by nutrients.

The secretion of these incretin hormones is intimately linked to autonomic nervous system activity [24]. Thus, the sympathetic hyperactivity and parasympathetic withdrawal associated with OSA are likely mediators of its adverse effects on glucose tolerance. The ability of OSA to activate the sympathetic nervous system is well characterized [25]. Increased sympathetic nerve activity is implicated as a primary mechanism in the development of sustained hypertension in OSA patients. Since activating the sympathetic nervous system can also potentially impact insulin sensitivity, it has been proposed that increased sympathetic nerve activity may lead to insulin resistance in OSA patients.

However, the possibility remains that hypoxic activation of the sympathetic nervous system or an increase in circulating catecholamines contribute to the long-term progression of insulin resistance and metabolic function that may occur over decades in patients exhibiting OSA and obesity [26]. The hypoxic stress of OSA likely activates the hypothalamic-pituitary-adrenal (HPA) axis, elevates cortisol levels and putatively contributes to insulin resistance. The downstream sequelae of OSA impact a vast array of organ systems and cellular processes [25]. It is suggested that OSA is an independent risk factor for the development of T2DM and that as many as $15-30 \%$ of patients with OSA have this comorbidity. Also, as the severity of OSA increases, incidence of T2DM also increases [26]. The association between OSA and T2DM further compounds or aggravates the effect of OSA on cardiovascular health. Screening for cardiovascular disease and T2DM is part of routine healthcare. However, despite the fact that OSA is common and affecting $24 \%$ and $9 \%$ of men and women respectively, it is estimated that $80-90 \%$ of people with OSA remain undiagnosed [27]. It is very difficult to ignore the public health costs of undiagnosed OSA especially given its association with cardiovascular disease and diabetes [28].

There are several possible mechanisms by which OSA could be associated with glucose intolerance and T2DM. Severe OSA results in an increased neurogenic sympathetic activity and circulating levels of nor-epinephrine, which could result in increased glycogenolysis, lipolysis, and insulin resistance. It is also possible that sleep disordered breathing (SDB) leads to release of cortisol resulting in higher glucose concentration and excessive insulin secretion. Yet another possibility is that adipocyte-derived inflammatory mediators, such as IL6 , TNF- $\alpha$, and leptin, which are released as a result of cyclic hypoxia, contribute to insulin resistance and hyperglycemia. Sleep loss and poor sleep quality have been associated with the risk of T2DM [29]. The association of obstructive sleep apnea (OSA) syndrome with obesity, hypertension and cardiovascular disease has highlighted the broad public health importance of this condition.

\section{Prevalence of OSA in Patients with Type 2 Diabetes Mellitus}

A number of studies have explored the prevalence of OSA in patients with T2DM. As illustrated in Table 1, the prevalence of OSA is alarmingly elevated in patients with T2DM. Among patients with OSA, the prevalence of T2DM has been estimated to be $15-30 \%$, with higher prevalence in those with severe OSA [30]. 


\section{Current Research in Diabetes \& Obesity Journal}

Table 1: Prevalence of OSA in Patients with Type 2 Diabetes.

\begin{tabular}{|c|c|c|c|c|c|c|c|c|}
\hline Reference & $\mathbf{N}$ & Setting & $\begin{array}{l}\text { Mean Age } \\
\text { (yrs) }\end{array}$ & $\begin{array}{l}\text { Mean BMI } \\
\mathrm{kg} / \mathrm{m} 2\end{array}$ & Male\% & Sleep Assessment & $\begin{array}{c}\text { Follow } \\
\text { Up (yrs) }\end{array}$ & Results \\
\hline$[31]$ & 318 & Australia & 53.1 & 26.6 & 41.3 & $\begin{array}{l}\text { RDI }>5 \text { from } 4 \mathrm{a}-\text {-channel } \\
\text { home monitoring device } \\
\text { (heart rate, oxygen } \\
\text { saturation, snoring and } \\
\text { body position) }\end{array}$ & 4 & $\begin{array}{c}\text { Moderate to severe OSA } \\
(\mathrm{RDI} \geq 15) \text { was associated } \\
\text { with diabetes, OR } 13.45 \\
(95 \% \text { CI } 1.59-114.11)\end{array}$ \\
\hline$[32]$ & 43,98 & Japan & 57.6 & 23.5 & 34.7 & $\begin{array}{l}3 \% \text { ODI } \geq 5 \text { events } / \mathrm{h} \text { using } \\
\text { pulse oximetry }\end{array}$ & 3 & $\begin{array}{c}\text { Moderate OSA (ODI } \geq 15) \\
\text { was associated with } \\
\text { diabetes, HR } 1.69(95 \% \text { CI } \\
1.04-2.76)\end{array}$ \\
\hline [33] & 47093 & U.S. & 36.7 & 26.3 & 25.3 & $\begin{array}{l}\text { Report of a physician } \\
\text { diagnosis of OSA }\end{array}$ & 6 & $\begin{array}{c}\text { OSA was associated with } \\
\text { diabetes, OR } 1.78(95 \% \mathrm{CI} \\
1.39-2.28)\end{array}$ \\
\hline$[34]$ & 8,678 & Canada & 48 & 28.4 & 62 & $\begin{array}{c}\mathrm{AHI} \geq 5 \text { by } \\
\text { polysomnography }\end{array}$ & 5 & $\begin{array}{c}\text { AHI }>30 \text { was associated } \\
\text { with diabetes, HR } 1.31 \\
(95 \% \text { CI } 1.07-1.61)\end{array}$ \\
\hline
\end{tabular}

\section{OSA and Nocturnal Blood Glucose}

The increased blood glucose levels and insulin resistance may lead to nocturnal hyperglycemia which occurs as a result of increased insulin secretion from beta cells. Nocturnal hypoxemia triggers hyperglycemia in patients who have both OSA and diabetes. The obstructive events which occur during sleep result in drop in blood oxygen levels which return to base level when the person's breathing resumes. As a result of this airway obstruction and multiple arousals that occur during the night, people have sleep fragmentation and often experience daytime sleepiness. In healthy subjects, sleep restriction is associated with insulin resistance, increased appetite and carbohydrate craving and even in the absence of breathing disorders sleep fragmentation and sleep deprivation can affect glucose tolerance.

Nocturnal awakening and arousal are associated with altered levels of leptin, leptin resistance, pulsatile cortisol release and autonomic activation. Repeated arousal and subsequent cortisol release can lead to dysregulation of the hypothalamicpituitary adrenal axis, which results in glucose impairment [35]. In 10 years follow up study by Al-Delaimy, et al. [36] 69852 nurses aged 40-65 years, it was found that regular snoring was independently associated with a two-fold increased risk of developing diabetes.

However, because of the lack of awareness by the public and healthcare professionals, the vast majority remains undiagnosed and untreated. It's estimated that about $70 \%$ of those with OSA are obese. The prevalence of OSA in obese men and women is about $40 \%$ [25]. Interestingly there is evidence to suggest that T2DM independently increases the likelihood of sleep disordered breathing possibly through the effects of diabetes on the autonomic and central nervous system [26].

\section{Screening of OSA in Patients with Type-2 Diabetes} Mellitus

Since there are evidences of high prevalence of OSA in patients with T2DM, there is need of increasing awareness of OSA amongst diabetes societies. In 2008 and 2017 the International Diabetes Federation's Taskforce on Epidemiology and Prevention and American Diabetes Association respectively strongly recommended that health professionals working in both T2DM and sleep-disordered breathing must consider screening a patient presenting with one condition for the other [37]. Therefore, given the high prevalence of OSA in patients with T2DM and the suboptimal performance of screening questionnaires, clinicians must consider exploring the diagnosis of OSA using home sleep monitoring devices if clinically appropriate.

\section{Management of OSA}

Treatment to control the signs and symptoms of OSA includes behavioral approaches to improving sleep habits and weight control. Both medical and surgical weight loss significantly reduce the severity of OSA. More recently, weight loss related to lifestyle interventions in people with type 2 diabetes has been shown to significantly improve OSA severity. Along with lifestyle modifications, there are also some mechanical as well as pharmacological options of OSA [38].

\section{Positive airway pressure (PAP)}

The elimination of nocturnal apneic events and intermittent hypoxia are the key goals to control OSA effectively. PAP devices function as a pneumatic support that allows one to maintain upper airway patency by increasing the upper airway pressure above a 'critical' value (pressure value below which the airways collapse). The device is applied to the patient, through a nasal or oronasal mask, overnight or during sleep hours at a set positive pressure. The pressure to apply can vary with the severity of OSA and higher pressures are needed to abolish those apnea's occurring during rapid eye movement sleep, in the supine position or in the presence of severe obesity. For each patient, the effective pressure is obtained after one or more nights of PAP titration. PAP therapy is indicated in all patients with an AHI greater than 15, independently from the presence of comorbidities, type of work and severity of symptoms [39]. 


\section{Continuous positive airway pressure (CPAP)}

For moderate to severe sleep apnea, the use of a continuous positive airway pressure (CPAP) is the first line therapy. CPAP uses continuous pressurized air flow to keep the individual's airway open during sleep. The amount of pressure used is initially titrated during the PSG (split test) based on the patient's comfort and lowest pressure required to decrease apneic and hypo apneic episodes. CPAP therapy is the most effective treatment option in reducing apneas in OSA. It has been shown to improve AHI, RDI, sleep architecture, EDS, neurobehavioral performance and cardiovascular morbidity (hypertension) [40].

\section{Dental appliances}

Dentists specializing in sleep dentistry make a custommade mouthpiece that shifts the lower jaw forward, thereby maintaining an open airway. In a study comparing CPAP to dental appliance in mild to moderate OSA, dental appliances decreased AHI from 21 (baseline) to 14, compared to decreased AHI of 5 in patients using CPAP [41].

\section{Surgical interventions}

Surgical treatment for OSA needs to be individualized in order to address all anatomical areas of obstruction. The most frequently utilized surgery treatment is the uvulopalatopharyngoplasty (UPPP or UP3). These surgeries aim to address pharyngeal obstruction by removing tissue in the back of the throat, including part of the uvula, the soft palate, the tonsils, the adenoids and pharynx [42].

\section{Maxillo-mandibular advancement (MMA)}

MMA is another type of surgery that has been used to treat OSA. This procedure aims to advance the maxilla and mandible, thereby pulling forward the anterior pharyngeal tissues attached to the maxilla, mandible and hyoid to structurally enlarge the retro lingual and retropalatal spaces. It is considered the most effective surgery for OSA patients, because it increases the posterior airway space. In a study in 2008, it was noted that MMA surgery led to a significant increase in general productivity, social outcome, activity level and sex [43].

\section{Pharmacological management of OSA}

Medications are generally not a part of the primary treatment of OSA. Modafinil is approved by the FDA for use in patients with OSA who have residual daytime sleepiness. Armodafinil, the R-enantiomer of modafinil, is now FDA approved for use as well. The American Academy of Sleep Medicine (AASM), in a clinical review of medical therapies for OSA, recommended Modafinil as a standard treatment of residual excessive daytime sleepiness in patients with OSA despite maximal management of CPAP [44].

\section{Conclusion}

OSA, via sympathetic activation, oxidative stress, inflammation, and neuroendocrine dysregulation, alters glucose homeostasis, including in-patients with type 2 diabetes. Early recogni- tion and interventions for OSA are expected to improve insulin sensitivity and control hyperglycemia in many patients. Both disorders are associated with adverse cardiovascular morbidity and mortality. Since there are evidences of high prevalence of OSA in patients with diabetes, there is need of increasing awareness of OSA amongst diabetes societies as is recommended by the American Diabetes Association. Clinicians need to be vigilant in screening and treating diabetic patients for OSA. Therefore, given the high prevalence of OSA in patients with type 2 diabetes, clinicians must consider exploring the diagnosis of OSA along with treatment options for both the diseases.

\section{References}

1. LJ Epstein, Kristo D, Strollo PJ, Friedman N, Malhotra A, et al. (2009) Clinical guideline for the evaluation management and long-term care of obstructive sleep apnea in adults. J Clin Sleep Med 5(3): 263-276.

2. S Pamidi, RS Aronsohn, E Tasali (2010) Obstructive sleep apnea: Role in the risk and severity of diabetes. Best Pract Res Clin Endocril Metab 24(5): 703-715.

3. KA Stamatakis, NM Punjabi (2010) Effects of Sleep Fragmentation on Glucose Metabolism in normal Subjects. Chest 137(1): 95-101.

4. O Kareem, M Tanvir, A Naqash, G Bader (2018) Obstructive Sleep Apea: A Risk Factor for Hypertension. J Cardiol Cardiovasc Sci 2(2): 20-28.

5. ME Dyken, K Bin Im (2009) Obstructive Sleep Apnea and Stroke. Chest 136(6): 1668-1677.

6. CM Schröder, RO’Hara (2005) Depression and Obstructive Sleep Apnea (OSA). Ann Gen Psychiatry 4: 13.

7. Rasche K, Keller T, Tautz B, Hader C, Hergenc G, et al. (2010) Obstructive sleep apnea and type 2 diabetes. Eur J Med Res 15(suppl 2): 152-156.

8. JM Joshi (2015) Obstructive Sleep Apnea and its Prevalence in India. Respi Mirror 5(1): 1-2.

9. Long AN, Dagogo-Jack S (2011) Comorbidities of Diabetes and Hypertension: Mechanisms and Approach to Target Organ Protection. J Clin Hypertens 13(4): 244-251.

10. Shaw JE, Sicree RA, Zimmet PZ (2010) Global estimates of the prevalence of diabetes for 2010 and 2030. Daibetes Res Clin Pr 87(1): 4-14.

11. (2019) Diabetes. World Health Organization.

12. (2012) Diagnosis and Classification of Diabetes Mellitus. Diabetes Care 35(suppl 1): S64-S71.

13. B Deepthi, K Sowjanya, B Lidiya, R Bhargavi, P Babu (2017) A Modern Review of Diabetes Mellitus: An Annihilatory Metabolic Disorder. J Silico Vitr Pharmacol 3: 1 .

14. ML Ho, SD Brass (2011) Obstructive sleep apnea Neurol Int 3(3): 15

15. Meisinger C, Heier M, Loewel H (2005) Sleep disturbance as a predictor of type 2 diabetes mellitus in men and women from the general population. Diabetologia 48(2): 235-241.

16. Punjabi NM, Sorkin JD, Katzel LI, Goldberg AP, Schwartz AR, et al. (2002) Sleep-disordered Breathing and Insulin Resistance in Middleaged and Overweight Men. Am J Respir Crit Care Med 165(5): 677-682.

17. Spiegel K, Leproult R, Van Cauter E (1999) Impact of sleep debt on metabolic and endocrine function. Lancet 354(9188): 1435-1439.

18. S Reutrakul, B Mokhlesi (2017) Obstructive Sleep Apnea and Diabetes. Chest 152(5): 1070-1086. 
19. Newhouse LP, Joyner MJ, Curry TB, Laurenti MC, Man CD, et al. (2017) Three hours of intermittent hypoxia increases circulating glucose levels in healthy adults. Physiol Rep 5(1): e13106.

20. Oltmanns KM, Gehring H, Rudolf S, Schultes B, Rook S, et al. (2004) Hypoxia Causes Glucose Intolerance in Humans. Am J Respir Crit Care Med 169(11): 1231-1237.

21. Somers VK, Dyken ME, Mark AL, Abboud FM (1993) Sympathetic nerve activity during sleep in normal subjects. N Engl J Med 328(5): 303-307.

22. Narkiewicz K, Kato M, Phillips BG, Pesek CA, Davison DE, et al. (1999) Nocturnal continuous positive airway pressure decreases daytime sympathetic traffic in obstructive sleep apnea. Circulation 100(23): 2332-2335.

23. Bloom SR, Edwards AV, Hardy RN (1978) The role of the autonomic nervous system in the control of glucagon insulin and pancreatic polypeptide release from the pancreas. J Physiol 280: 9-23.

24. Ahrén B, Holst JJ (2001) The Cephalic Insulin Response to Meal Ingestion in Humans Is Dependent on Both Cholinergic and noncholinergic Mechanisms and Is Important for Postprandial Glycemia. Diabetes 50(5): 1030-1038.

25. Doumit J, Prasad B (2016) Sleep Apnea in Type 2 Diabetes. Diabetes Spectr 29(1): 14-19.

26. Dempsey JA, Veasey SC, Morgan BJ, O’Donnell CP (2010) Pathophysiology of Sleep Apnea. Physiol Rev 90(1): 47-112.

27. Young T, Evans L, Finn L, Palta M (1997) Estimation of the clinically diagnosed proportion of sleep apnea syndrome in middle-aged men and women. Sleep 20(9): 705-706.

28. Aurora (2015) Obstructive Sleep Apnea and Type 2 Diabetes Mellitus: Examining the Evidence. Am Coll Cardiol.

29. Mahmood K, Akhter N, Eldeirawi K, Onal E, Christman JW, et al. (2009) Prevalence of Type 2 Diabetes in Patients with Obstructive Sleep Apnea in a Multi-Ethnic Sample. J Clin Sleep Med 5(3): 215-221.

30. Marshall NS, Wong KK, Phillips CL, Liu PY, Knuiman MW, et al. (2009) Is sleep apnea an independent risk factor for prevalent and incident diabetes in the Busselton Health Study? J Clin Sleep Med 5(1): 15-20.

31. Celen YT, Hedner J, Carlson J, Peker Y (2010) Impact of gender on incident diabetes mellitus in obstructive sleep apnea: a 16-year followup. J Clin Sleep Med 6(3): 244-250.

32. Muraki I, Tanigawa T, Yamagishi K, Sakurai S, Ohira T, et al. (2010) Nocturnal intermittent hypoxia and metabolic syndrome; the effect of being overweight: the CIRCS study. J Atheroscler Thromb 17(4): 369377.
33. Boyko EJ, Seelig AD, Jacobson IG, Hooper TI, Smith B, et al. (2013) Sleep Characteristics Mental Health and Diabetes Risk: a prospective study of U S military service members in the Millennium Cohort Study. Diabetes Care 36(10): 3154-3161.

34. Kendzerska T, Gershon AS, Hawker G, Tomlinson G, Leung RS (2014) Obstructive Sleep Apnea and Incident Diabetes A Historical Cohort Study. Am J Respir Crit Care Med 190(2): 218-225.

35. Feng Y, Zhang Z, Dong ZZ (2015) Effects of continuous positive airway pressure therapy on glycaemic control insulin sensitivity and body mass index in patients with obstructive sleep apnoea and type 2 diabetes: a systematic review and meta-analysis. NPJ Prim Care Respir Med 25(1): 15005.

36. Al-Delaimy WK, Manson JE, Willett WC, Stampfer MJ, Hu FB (2002) Shoring as a Risk Factor for Type II Diabetes Mellitus: A Prospective Study. Am J Epidemiol 155(5): 387-393.

37. Shaw JE, Punjabi NM, Wilding JP, Alberti KG, Zimmet PZ (2008) Sleepdisordered breathing and type 2 diabetes. Diabetes Res Clin Pract 81(1): 2-12.

38. Neill AM1, Angus SM, Sajkov D, McEvoy RD (1997) Effects of sleep posture on upper airway stability in patients with obstructive sleep apnea. Am J Respir Crit Care Med 155(1): 199-204.

39. Cao MT, Sternbach JM, Guilleminault C (2003) Continuous positive airway pressure therapy in sleep apea. Respirology 8(4): 447-454.

40. Stepnowsky CJ Jr, Moore PJ (2003) Nasal CPAP treatment for obstructive sleep apnea: developing a new perspective on dosing strategies and compliance. J Psychosom Res 54(6): 599-605.

41. Machado MA, Juliano L, Taga M, de Carvalho LB, do Prado LB (2007) Titratable mandibular repositioner aliances for obstructive sleep apnea syndrome: are they an option? Sleep Breath 11(4): 225-231.

42. Won CH, Li KK, Guilleminault C (2008) Surgical Treatment of Obstructive Sleep Apnea: Upper Airway and Maxillomandibular Surgery. Proc Am Thorac Soc 5(2): 193-199.

43. Prinsell JR (2002) Maxillomandibular advancement surgery for obstructive sleep apnea syndrome. J Am Dent Assoc 133(11): 14891497.

44. Abad VC, Guilleminault C (2011) Pharmacological treatment of obstructive sleep apnea. Curr Pharm Des 17(15): 1418-1425.

Your next submission with Juniper Publishers will reach you the below assets

- Quality Editorial service

- Swift Peer Review

- Reprints availability

- E-prints Service

- Manuscript Podcast for convenient understanding

- Global attainment for your research

- Manuscript accessibility in different formats

( Pdf, E-pub, Full Text, Audio)

- Unceasing customer service

Track the below URL for one-step submission

https://juniperpublishers.com/online-submission.php 